\title{
Vitamin-D and Covid-19: An Updated Review
}

\author{
Sheba Ann Varghese and Swaroopa Chakole \\ Department of Community Medicine, Jawaharlal Nehru Medical College, Datta Meghe Institute of Medical \\ Sciences (Deemed to be University), Sawangi (Meghe), Wardha-442001, Maharashtra, India \\ Corresponding author email: drswaroopachakole@gmail.com
}

\section{ABSTRACT}

The most dreaded pandemic of the century is COVID-19. It is widely seen that persons with already having chronic illnesses or comorbidities( Guan et al., 2020) such as diabetes , hypertension, liver failure, bronchial disease, renal failure, tuberculosis are most vulnerable and need extreme medical attention with hospitalization in almost all the cases. Even if at lower age the comorbidity can be deciding factor in deciding the severity of the cases reported. The comorbid patients are confirmed to be producing more severe symptoms than any other patients. The role of vitamin D is promising. The new buzz word in the treatment boulevard is vitamin D and its effects in treating the patients suffering from acute respiratory distress syndrome (ARDS). It is said to be beneficial in treating COVID-19 cases to where immunomodulation is required. Vitamin D with empirical evidence can prove as magic bullet for infected health care workers who are on the frontline. The amount of Vitamin D which is generally synthesized by the body through exposure of the sun is lessen due to home confinement as a result of lockdown measure. So various other mechanisms for delivering safe and minimum daily requirement of vitamin D through ground workers will be a key element in reducing the worsening of symptom condition. This study tries to review the correlation between vitamin $\mathrm{D}$ and its positive and negative effects with respect to COVID-19 treatment.

\section{KEY WORDS: VIT. D,COVID-19, HEALTHCARE WORKERS, IMMUNOMODULATORY, SAFE DOSES.}

\section{INTRODUCTION}

The most dreaded pandemic of the century is COVID19. Named after crown shaped coronavirus by World Health Organization, which has capability to rapidly and exponentially grow from zero to all over the world. The worst lockdown since Second World War was seen in this time. Global infected cases touched at 45,967,061(1) (around 46 million cases worldwide), global deaths due to infection of the COVID-19 stood at 1,194,325 as of November 1, 2020(1). United States of America, Republic of India, Brazil, Russian federation, France and Spain these are the top countries who only accounts for more than half of the world-wide cases reported authentically

Biosc Biotech Res Comm P-ISSN: 0974-6455 E-ISSN: 2321-4007

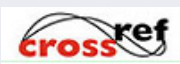

Identifiers and Pagination

Year: 2021 Vol: 14 No (6) Special Issue

Pages: 186-191

This is an open access article under Creative

Commons License Attribn 4.0 Intl (CC-BY).

DOI: $h t t p: / / d x . d o i . o r g / 10.21786 /$ bbrc/14.6.40 which is a cause of grave concern. Initially the nonpharmacological measure or interventions (NPI) like lockdown(2)which was varying in strictness in various countries, physical distancing, prohibition of gatherings, mask wearing, maintaining minimum safe distance from each other, movement restriction was imposed so that the virus on which almost no information was available could be contained.

The major case fatality rates that the world saw in china and then Italy and Spain touching nearly 10 thousand deaths each day frightened the world community over the to the Americas where it is wreaking havoc after creating ruckus in Europe. Now almost around 8 to 9 months are passed some conclusive evidence and correlation are established which are useful in guiding the containment strategy of the COVID-19. The death toll was and is still on rise with no peak achieved. The deaths among the health care professionals is a cause of concern in already disturbing many. The recent announcement from the International Council of Nurses claimed(3) that the world. Now the virus has shifted its epicenter from Europe

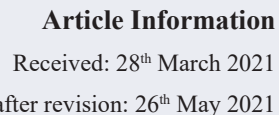

ccepted after revision: $26^{\text {th }}$ May 2021 
number of nurses died in First World War and number of nurses died while on COVID-19 duty have reached same level with later overtaking the former already. It is widely seen that persons withalready having chronic illnesses or comorbidities(4) such as diabetes, hypertension, liver failure, bronchial disease, renal failure, tuberculosis are most vulnerable and need extreme medical attention with hospitalization in almost all the cases.

Even if at lower age the comorbidity can be deciding factor in deciding the severity of the cases reported. The stark difference between men and women patients case fatality rate despite their same affinity towards the virus contraction is an interesting yet insightful issue upon which more research needs to be done. The new buzz word in the treatment boulevard is vitamin $\mathrm{D}$ and its effects in treating the patients suffering from acute respiratory distress syndrome (ARDS). It is said to be beneficial in treating COVID-19 cases to where immunomodulation is required. Vitamin D if proven with empirical evidence can prove as magic bullet for infected health care workers who are on the frontline. The amount of Vitamin D which is generally synthesized by the body through exposure of the sun is lessen due to home confinement as a result of lockdown measure.

So various other mechanism for delivering safe and minimum daily requirement of vitamin $\mathrm{D}$ through ground workers will be a key element in reducing the worsening of symptom condition. Too much consumption of vitamin D in order to quickly fill up the gap will do only harm and can cause vitamin D toxicity which leads to accumulation of calcium in kidneys and people can experience nausea and vomiting. So proper, safe and minimum amount must be ensured for intake. Self-medication is what various agencies are finding it difficult to deal with and has equal potential of virus to increase case fatality rate. Immunity booster diet is already finding its way to the people with health consciousness and now it is targeting all the people for good only. Maintaining certain amount of immunity power which can be used to fight the virus like this is like preparing in silence before war. All these aspects are covered under this article which take a comprehensive overview of the current scenario in COVID-19 pandemic.

Vitamin D: Vitamin D also known as calciferol is a fat-soluble vitamin. It is widely known that apart from few food sources it is extensivelyproduced after threshold sun exposure which triggers its production in body. The biologically inactive substance undergoes two hydroxylation. The vitamin $\mathrm{D}$ is converted to 25-hydroxyvitamin D [25(OH) D] or calcidiol in first hydroxylation. In second hydroxylation process the substance known as 1, 25-dihydroxyvitamin D [1, 25(OH) 2D] or calcitriol. Vitamin D stimulates the absorption of calcium which is digested by the intestine and sourced from the ingested food material. Calcium and Vitamin $\mathrm{D}$ is extremely necessary in the development of bones. Osteoporosis can be a result if necessary, amount of the Vitamin D and calcium intake is there.
The food sources include various types' fishes including salmon, sardines, herring, tuna etc. which provides enough quantity of Vitamin D to complete the daily quota. Daily Vitamin D intake which should everyone consume varies according to the age group. For infants it is from 24 micrograms to 36 micrograms (Jovic et al., 2020), for children up to 8 years it is 62 micrograms to 76 micrograms and for adults in this case person above 9 years and above needs at least 100 micrograms of Vitamin D per day. These make up to around 1000IU, 2500IU and 4000IU respectively. The main chunk of the Vitamin D is induced by sun exposure. Therefore, lack of Vitamin D is prevalent in all over the world. Brittle bones, unshaped bones, weakness, osteoporosis can be a result of low Vitamin D generation due to suns exposure. Various reasons are responsible for the low exposure of sun rays.

Weather, pollution, dust particles, indoor work, clothes which prohibits the sun to penetrate the skin. These problems of exposure are somewhat hard to fight but it is essential as till now we have not achieved the fortification of foods with Vitamin D. The low vitamin D diet which is mostly junk or couch food is extremely harmful in all ways. Even if a person doubles its intake of calcium then it would benefit nothing as the absorbing agent is not present which vitamin D is in this case (Weir et al., 2020). Lack of vitamin D is also linked to the profession and altitude. In case of profession where the person works more rigorous work in fields such as laborers and farmers are less prone to vitamin D deficiency whereas indoor jobs like desktop and laptop jobs which requires the person to be sit at one place generally away from the sunlight in order to maintain its energy levels are more likely to be vitamin $\mathrm{D}$ deficient.

Vitamin D and Covid-19: As this deadly pandemic is progressing it also leaving certain trends to study and think upon to effectively chalk out the plan to contain the virus. In the first fortnight of the march World Health Organization (WHO) has announced the COVID-19 as pandemic (Ribeiro et al., 2020), since then various measures are employed to contain the virus and defenestrate it from the society which is now posing a grave threat to human civilization as a whole. The non-pharmacological measures announced by various governmental agencies and health care authorities such as lockdown, physical distancing, mask wearing, personal and protective equipment which can be worn off only after the duty hours has created another problem. Due to lockdown the physical activity and exercises which are necessary in order to maintain the body, mind, souk balance is completely disturbed. Indoor exercise do not cover all the aspects of the outdoor exercise (Grant et al., 2020).

In addition, the main stimulator the sun which on exposure to the skin starts the production of vitamin $\mathrm{D}$ and further the absorption of calcium, an essential component of the strength giving organ that is bone, was completely absent. People were unable to access the sunlight for required amount of the time they need. Lack 
of access to terrace or lack of terrace itself paired with movement restrictions and closure of open gymnasium and other such institutions can take a huge toll on bone density and possibility of osteoporosis in people where the vitamin D is already deficient due to their sedentary and under shadow lifestyle can increase.

In elderlies where the vitamin D concentration levels are already low, they suffer from various comorbidities arising out of the same. Vitamins of all types and minerals too are important in the day to day functioning of the body. If it is not maintained the bodily balance is disturbed and immunity system is weakened over the period of time. As far as comorbidity is concern with respect to the COVID-19, it is now clearly established by clinical studies that it is the biggest factor in deciding the severity of the COVID-19 cases. The Acute respiratory distress syndrome (ARDS)(Singh et al., 2020) which is the primary result of influenza like illnesses has been lowered if vitamin $\mathrm{D}$ is present in higher and sufficient amount. The pneumocytes apoptosis is known to be reduce the ARDS and prevent severe lung injury arising out of it.

Vitamin D is also related to immune response which is crucial in fighting the deadly spread of coronavirus. Various study has shown that the respiratory and renal failure, rate of infection is closely linked with the availability of the vitamin D in the body. Recently a study published discovered some relation between the treatment and severity of the symptoms and levels of the COVID-19(10). The new function performed by vitamin $\mathrm{D}$ as immunomodulatory is being closely followed and studied across the spectrum. Possible treatment of COVID-19 which also can be used as prophylactic to prevent the disease from happening at first place is really promising.

A lot has changed since the initial days of the pandemic. Initially the most talked about drug was hydroxychloroquine (HCQ), but it was beneficial in limited ways which was them halted to be used as treatment. Later plasma therapy, Remdesivir, lopinavirs were all said to be the panacea for the deadly COVID-19 but only proved to be of limited use. Even the plasma therapy has to be abandoned in some countries provided no use. There is a need of complex in more curated mixture of medicine to be provided to the patient so that it can get treated successfully.

A study (Meltzer et al., 2020) conducted on around 489 patients in United States of America shows relation between the vitamin $\mathrm{D}$ levels and risk of contracting the COVID-19. When deficiency leveled at 20 nomograms per milliliter of the blood, the patients with the vitamin D level below this threshold were 1.77 times higher prone as compared to those who has this level present in their blood. Supplements were advised to those with lesser than threshold value. Here western countries have more awareness about the fortification of foods with vitamin $D$ to ensure minimum intake than eastern low per capita income category. The high prevalence of vitamin D deficiency is prevalent. Sunlight induced vitamin D production should be complemented by fortified foods so that professionals with sedentary and indoor work culture can benefit from it.

Delivering Mechanism for Vitamin D: Severe acute respiratory syndrome (SARS-COV-2) has a spike protein which gets attached to the ACE2 receptor and the respiratory distress arises. Comorbid patients have shown prominent ACE2 receptors which are readily gets attached with the spike protein of the virus, hence they are more vulnerable. Vitamin D is found out to be relieving the distress and an in-hand tool to lessen the burden on ailing health infrastructure. Countries where health infrastructure is on the verge of the collapse can try providing the supplementation of the vitamin D at first stage to prevent it from happening.

The anti-inflammatory response of the aforementioned vitamin can be used to prevent more severe symptoms which need critical care to handle. Suggested oral dosage of 4000 to 5000 IU (Arboleda et al., 2020) of vitamin $\mathrm{D}$ can be administered through ground health care workers and people can be advised to eat vitamin $\mathrm{D}$ fortified foods if available. Lowering infection rate at first place immensely benefits the containment measures than concentrating on reducing case fatality rate after hospitalizing. With this the long-term impact on patients which can create complications in the future also gets eliminated. Again, proper note of contraindications and over dosage should be avoided.

Role of Immune Booster Diet: The strong link between immunity and the susceptibility of the COVID-19 suggested that when the patient has weakened its immunity due to any other disease which is of chronic type is more prone to show more severe result than the person with less or zero disease have less chance of the same. As we know that we are what we eat the diet is closely linked to the immune response (Infusino et al., 2020) provided by the body when external unwanted actors attacks the body. The less and wholesome you eat the less is the oxidative stress develops which in turn increases the immunity power. It is seen in COVID-19 cases that some foods having anti-oxidants and antiinflammatory properties have huge impact in building the immunity and thus keeping away influenza like illnesses.

Though proper and empirical data is needed to establishthe same. The general food which are considered immunity booster tried and found to be effective in such scenario. Foods such as vitamin C (Arshad et al, 2020), vitamin D (Mitchell et al., 2020) can be used as prophylactics after proper trials which are known to reduce oxidative stress and inflammatory tissues. Vitamin D especially is helping the workers and professionals who have to work in the fields and they are sufficiently exposed to the natural sunlight which is the pre requisite for the stimulation of the Vitamin D and in turn in the absorption of the calcium from the intestine which is essential for osteocytes. 
Even in the infected patient diet plays importantrole as comorbid patients have welcomed these comorbidities by eating unhealthy stuffs and not taking fibers included products and vitamin $\mathrm{C}$ and vitamin $\mathrm{D}$ in sufficient mount. Its never too late as proper curated diet can be prepared to aid the treatment that is given alongside. With adhering to the contraindications provided for the patient which is being treated, one can easily single out essential beneficial food list which will act as quasi medicine. Changing the dietary habits and inculcating proper and beneficial habits can not only help in controlling the frequent occurrences of the diseases but also, we will be future ready with strong immunity if such large-scale pandemic hits again.

Self-Medication in Covid-19 Pandemic: The fear of contracting the pandemic has led to people being confined at home. In the era of internet explosion and unprecedented penetration of the internet and information with the mobile phones being cheaper day by day, most of the people are spending their major chunk of the day on the mobile. Especially social networking sites which are meant to bring the world more closely, are attracting majority of the traffic. Therefore,naturally one would quench its thirst of information from the internet itself which is handy, portable and cheaper nowadays. So many malicious information or misinformation which WHO termed as Infodemic (Solomon 2020) is creating a parallel challenge of another information pandemic along with the clinical one. The menace is so huge that it is showing extremely negative result and many people are prone to the abovementioned phenomenon.

This fact makes it even more dangerous. False information about testimonies from the patients that supposedly cured and asking people to treat themselves only at home, medical negligence hoax, unnecessary and false information with no proper empirical backing are some of the manifestations of the Infodemic (Ather Ather et al., 2020). Many Covid related reviews from this region were reported (Toshida, 2020; Jachak,2020). Self-medication is most prevalent in pandemic times without consulting the doctor as the measures such as lockdown and physical distancing force people to do this. Wrong medications can create unwanted complications and may be fatal. Government and various information bureaus are keen on wiping out this information but thesespread like wild fire. Only a counter fire with same vigor can doze off the fire of misinformation.

Overdose of vitamins tablets after becoming a popular medicine for treating the patients in COVID-19 ward is gaining stronghold. (Juneja et. al., 2020) and (Kambale et. al., 2020) reported the reviews on Vit. D supplementation during Covid-19.A number of studies on roles of different vitamins in various conditions were reported (29-32). Contraindications varies from person to person and according to the condition therefore proper consultation is extremely necessary to avoid further self-medication induced complications. People being tricked into false testimonies of the nonexistent doctor who prescribed so and so medicine and advising people to not to take COVID-19 seriously and it is only kike other flus.

Layman has no time and knowledge about such misinformation and readily believes what is being served. Taking medicine in excess and not at all are being widely seen. Even after doctor advising to follow certain guidelines at home, peoples are reluctant and are completely aught in to the net of Infodemic. Such menace needs efforts at war footing with rigorous presence on social networking sites. Participation of civil society groups, NGO's, students can be a best trio along with authentic information from the government side will ensure that not much cases are added due to such reasons.

\section{CONCLUSION}

Ever changing scenario and its grave consequences arising out of COVID-19 needs keen attention. From comorbidities to scarcity of vitamin D to plasma therapy and so on, new trends are emerging which needs a proper evidenced based back up so that their result can be further used for not only for containing the coronavirus spread but also for future pandemics that cannot be out rightly rejected and there will always be a hanging sword on us. Vitamin D is making to the news circles of the COVID-19 researchers as it offers some promising outcomes and shown positive correlation in the benefit of the patient affected. Self-medication is yet another negative consequence of the lack of the access to proper healthcare during lockdown. People relying on false information that is circulating widely forcing them to try one how these medications work. One should always know their contraindications before taking medicines. On health authority's front, widespread authentic information camping needs to come into action so that myths can be dispel by awarded citizens and civil society groups. Immunity booster diet which was and is talk of the town must be studied deeply and these results can be used now as well as in future scenarios.

Finally, this pandemic offering some opportunities to look into the health care infrastructure, our lifestyle which is self-destructive and harming others. Condition of long COVID-19 is emerging as an undesirable trend which in the long run will do only harm. A second wave of COVID-19 itself is serious danger for all of us. Already the re-imposition of certain European countries is the testimony of the severity of the second wave of the coronavirus. We need to be more vigilant than ever before. Lifestyle is seen a major factor to decide any illness related complications. A major change is needed and policy shift is necessary to ensure that we are resilient in all aspects of our life.

\section{REFERENCES}

Arboleda JF, Urcuqui-Inchima S. Vitamin D Supplementation: A Potential Approach for Coronavirus/ COVID-19 Therapeutics? Front Immunol [Internet]. 2020 Jun 23 [cited 2020 Nov 1];11. https://www.ncbi.nlm.nih. 
gov/pmc/articles/PMC7324720/

Arshad MS, Khan U, Sadiq A, Khalid W, Hussain M, Yasmeen A, et al. 2020 Coronavirus Disease (COVID-19) and Immunity Booster Green Foods: A Mini Review. Food Sci Nutr. May 31;

Ather B, Mirza TM, Edemekong PF. 2020 Airborne Precautions. StatPearls [Internet], StatPearls Publishing 2020;Available from: https://www.ncbi.nlm.nih.gov/ books/NBK531468/

Butola, Lata Kanyal, Prakash KeshaoraoKute, Ashish Anjankar, Archana Dhok, Neelam Gusain, and Anjali Vagga. 2020 "Vitamin B12 - Do You Know Everything?" JOURNAL OF EVOLUTION OF MEDICAL AND DENTAL SCIENCES-JEMDS 9: 3139-46. https://doi.org/10.14260/ jemds/2020/688.

COVID-19 Facets: Pandemics, Curse and Humanity | International Journal of Research in Pharmaceutical Sciences [Internet]. [cited 2020 0ct 17]. Available from: https://pharmascope.org/ijrps/article/view/2731

COVID-19 Map Johns Hopkins Coronavirus Resource Center. https://coronavirus.jhu.edu/map.html

Dhok, Archana, Lata KanyalButola, Ashish Anjankar, Amol Datta Rao Shinde, Prakash KesharaoKute, and Roshan Kumar Jha. 2020 "Role of V i t a m i n s and Minerals in Improving Immunity during Covid19 Pandemic - A Review." JOURNAL OF EVOLUTION OF MEDICAL AND DENTAL SCIENCES-JEMDS 9: 2296-2300. https://doi.org/10.14260/jemds/2020/497. Gaidhane S, Khatib N, Zahiruddin QS, Gaidhane A, Telrandhe S, Godhiwal P. 2020 'Depression, anxiety and stress among the general population in the time of COVID-19 lockdown: A cross-sectional study protocol.' International Journal of Research in Pharmaceutical Sciences, 11(1), pp. 360-364.

Grant WB, Lahore H, McDonnell SL, Baggerly CA, French CB, Aliano JL, et al. 2020 Evidence that Vitamin D Supplementation Could Reduce Risk of Influenza and COVID-19 Infections and Deaths. Nutrients. 2;12-26. Guan W-J, Liang W-H, Zhao Y, Liang H-R, Chen Z-S, Li Y-M, et al. 2020 Comorbidity and its impact on 1590 patients with COVID-19 in China: a nationwide analysis. Eur Respir 55(5); 21-28.

ICN confirms 1,500 nurses have died from COVID-19 in 44 countries and estimates that healthcare worker COVID-19 fatalities worldwide could be more than 20,000 [Internet]. ICN - International Council of Nurses. [cited 2020 Nov 1]. Available from: https://www.icn.ch/ news/icn-confirms-1500-nurses-have-died-covid-1944-countries-and-estimates-healthcare-worker-covid Infusino F, Marazzato M, Mancone M, Fedele F, Mastroianni CM, Severino P, et al. 2020 Diet Supplementation, Probiotics, and Nutraceuticals in SARS-CoV-2 Infection: A Scoping Review. Nutrients.
Jun 8;12(6).

Jachak, S., P. Phansopkar, and M. Waqar Naqvi. 2020 "Impact of Covid-19 in India, a Disastrous Pandemic Outbreak." International Journal of Research in Pharmaceutical Sciences 11: 399-402. https://doi. org/10.26452/ijrps.v11iSPL1.2735.

Joseph, M.B., S. Pohekar, A. Raut, and M. Patil. 2020 "The Palliative Care and Covid-19 Pandemic." International Journal of Research in Pharmaceutical Sciences 11:618-22. https://doi.org/10.26452/ijrps. v11iSPL1.2861.

Joshi, K., N. Acharya, S. Acharya, and S. Joshi. 2020 "A Grave Situation with COVID in the Gravid: A Narrative Review." International Journal of Research in Pharmaceutical Sciences 11: 496-99. https://doi. org/10.26452/ijrps.v11iSPL1.2837.

Jovic TH, Ali SR, Ibrahim N, Jessop ZM, Tarassoli SP, Dobbs TD, et al. 2020 Could Vitamins Help in the Fight Against COVID-19? Nutrients. 23;12-19.

Juneja, S., S. Dangore-Khasbage, and R.R. Bhowate. 2020 "Role of Vitamin d in Prevention of Corona Virus Infection (Covid-19)." International Journal of Research in Pharmaceutical Sciences 11:1 (2020): 407-10. https:// doi.org/10.26452/ijrps.v11iSPL1.2737.

Kamble, A., R.S. Ambad, M. Padamwar, A. Kakade, and M. Yeola. 2020 "To Study the Effect of Oral Vitamin d Supplements on Wound Healing in Patient with Diabetic Foot Ulcer and Its Effect on Lipid Metabolism.” International Journal of Research in Pharmaceutical Sciences 11: 2701-6. https://doi.org/10.26452/ijrps. v11i2.2290.

Khatib, M.N., S. Gaidhane, M. Khatib, M. Ahmed, A. Gaidhane, and Z.Q. Syed. 2020 "SARS-CoV and SARSCoV-2: Similar Viruses with Different Trajectories." Wutan Huatan Jisuan Jishu 16, no. 5: 544-48.

Lakhkar, B.B., B. Guru, S. Damke, and S. Damke. 2020 "Most Susceptible Duo in COVID-19 Crisis: A Literature Review.” Perinatology 21:112-23.

Latchoumi, T.P., Ezhilarasi, T.P. and Balamurugan, K., 2019. Bio-inspired weighed quantum particle swarm optimization and smooth support vector machine ensembles for identification of abnormalities in medical data. SN Applied Sciences, 1(10), pp.1-10.

Meltzer D0, Best TJ, Zhang H, Vokes T, Arora V, Solway J. Association of Vitamin D Status and Other Clinical Characteristics With COVID-19 Test Results. JAMA Netw Open. https://jamanetwork.com/journals/ jamanetworkopen/fullarticle/2770157

Mitchell F. Vitamin-D and COVID-19: do deficient risk a poorer outcome? Lancet Diabetes Endocrinol [Internet]. 2020 Jul 1 [cited 2020 0ct 13];8(7):570. Available from: https://www.thelancet.com/journals/landia/article/ PIIS2213-8587(20)30183-2/abstract 
Mujawar, Jahir R., and S. S. Patel. 2020 "Circulating Biomarkers of Oxidative Stress in Preeclampsia and Efficacy of Antioxidant Vitamin C Supplementation." RESEARCH JOURNAL OF PHARMACEUTICAL BIOLOGICAL AND CHEMICAL SCIENCES 7: 14981506.

Ribeiro H, Santana KV de S de, Oliver SL, Rondó PH de C, Mendes MM, Charlton K, et al. 2020 Does Vitamin D play a role in the management of Covid-19 in Brazil? Rev Saude Publica. 54:53-61.

Shah, P., and Naqvi W. 2020 'Fighting And Chasing The Rogue Virus-Covid19'. International Journal of Research in Pharmaceutical Sciences, 11(1), 2020, pp. 77-80. DOI. org (Crossref), doi:10.26452/ijrps.v11iSPL1.2219

Singh S, Kaur R, Singh RK. 2020 Revisiting the role of vitamin D levels in the prevention of COVID-19 infection and mortality in European countries post infections peak. Aging Clin Exp Res. 32(8):1609-12.

Solomon DH, Bucala R, Kaplan MJ, Nigrovic PA. 2020
The "Infodemic" of COVID-19. Arthritis Rheumatol Hoboken NJ. 2020 Aug 2;

The Lancet null. India under COVID-19 lockdown. Lancet Lond Engl. 2020 25;395(10233):1315.

Toshida, T., and Chaple J. 2020 'Covid-19 - Rumours and Facts in Media'. International Journal of Research in Pharmaceutical Sciences, 11(1), 2020, pp.171-74. pharmascope.org, doi:10.26452/ijrps.v11iSPL1.2344.

Wasnik, Rina Raibhan, and Nilkanth Ramji Akarte. 2020 "Evaluation of Serum Zinc and Antioxidant Vitamins in Adolescent Homozygous Sickle Cell Patients in Wardha, District of Central India." JOURNAL OF CLINICAL AND DIAGNOSTIC RESEARCH 11: BC1-3. https://doi. org/10.7860/JCDR/2017/30855.10320.

Weir EK, Thenappan T, Bhargava M, Chen Y. 2020 Does vitamin D deficiency increase the severity of COVID-19? Clin Med Lond Engl. 20(4):e107-8.

WHO Director-General's opening remarks at the media briefing on COVID-19 - 11 March 2020.pdf. 